\title{
Impact of Advanced Patient Counseling Using a Training Device and Smartphone Application on Asthma Control
}

\author{
Haitham Saeed, Mohamed EA Abdelrahim, Hoda Rabea, and Heba F Salem
}

\begin{abstract}
BACKGROUND: Pressurized metered-dose inhalers (pMDIs) are among the most commonly used aerosol delivery devices. Poor lung deposition from a pMDI is often a result of incorrect inhalation technique. The aim of this study was to compare the impact of combining a newly released training device with a smartphone application (advanced counseling) in asthma control to the impact of traditional verbal training. METHODS: A total of 371 subjects with asthma were divided into 2 groups: advanced counseling $(n=187)$ and verbal counseling $(n=184)$. Both groups had 3 visits, each meeting being a month apart. At each visit, lung function (ie, $\mathrm{FEV}_{1}$, ratio of $\mathrm{FEV}_{1}$ to forced vital capacity $\left[\mathrm{FEV}_{1} / \mathrm{FVC}\right]$, and peak expiratory flow) were measured, an asthma control test was given, and subjects were trained in the correct inhalation technique. Inhalation flow through the pMDI was also recorded at each visit because the correct pMDI technique requires an inspiratory flow of $<60 \mathrm{~L} / \mathrm{min}$. RESULTS: In the advanced counseling group, lung function significantly improved after both the first and the second visit $(P<.001)$, whereas in the verbal group, lung function improved significantly only after the second visit $(P<.001)$. Although the inspiratory flow through the pMDI improved significantly in both groups, it was closest to the target range in the advanced counseling group. In addition, more subjects in the advanced counseling group had monthly increases of $\geq 3$ points in their asthma control test scores compared to the verbal counseling group. CONCLUSIONS: The use of a training device with a smartphone application in conjunction with traditional verbal counseling in pMDI technique resulted in significant improvements in asthma control compared to traditional verbal counseling in pMDI technique alone. Key words: pMDI; salbutamol; asthma; total emitted dose; counseling; asthma control. [Respir Care 2020;65(3):326-332. (C) 2020 Daedalus Enterprises]
\end{abstract}

\section{Introduction}

The pressurized metered-dose inhaler (pMDI) is one of the most commonly used aerosol-generating devices, and it has a high degree of suitability for many patients due to its portability and multi-dosing system. ${ }^{1}$ The major draw-

Drs Saeed, Abdelrahim, and Rabea are affiliated with the Clinical Pharmacy Department, Faculty of Pharmacy, Beni-suef University, Beni-suef, Egypt. Dr Salem is affiliated with the Pharmaceutics and Industrial Pharmacy Department, Beni-suef University, Beni-suef, Egypt.

The authors disclose a relationship with Clement Clarke International.

Correspondence: Mohamed EA Abdelrahim PhD, Department of Clinical Pharmacy, Beni-suef University, Ahmed Hegazi Tawil street, Beni-suef 62511, Egypt. E-mail: mohamedemam9@yahoo.com.

DOI: $10.4187 /$ respcare.06903 back to pMDI-delivered therapy is suboptimal inhalation technique, which is the result of a lack of coordination between the patient's inhalation and the aerosol discharge from the device. ${ }^{2}$ Effective patient education about correct pMDI inhalation technique is an urgent requirement because $<10 \%$ of patients use their pMDI correctly. ${ }^{3-5}$ Traditional verbal training includes 11 steps to ensure the correct use of the pMDI (Table 1), 4,5 most of which, in theory at least, are easily executed by the patient and easily checked by the trainer. These include shaking the device, exhaling before inhalation of the aerosol, and positioning the pMDI in the patient's mouth. ${ }^{4}$ Unfortunately, teaching the correct pMDI technique via verbal instruction at chest clinics and to elderly patients is inadequate for correcting coordination errors. ${ }^{3,4}$

Inhaling the emitted aerosol slowly and deeply for at least $5 \mathrm{~s}$ is a critical step in pMDI use because fast inhalation reduces lung deposition and increases oropharyn- 
geal deposition of the drug. ${ }^{6}$ Hence, fast inhalation reduces the efficacy of the pMDI and results in poor disease control. ${ }^{7-9}$ Optimal lung deposition of the emitted drug is achieved at an inspiratory flow through the pMDI of 30$60 \mathrm{~L} / \mathrm{min}$; however, basic verbal counseling cannot ensure that the patient inspiratory flow through the pMDI is within this range. ${ }^{3,4}$

Counseling conducted on a regular basis enhances therapy outcomes and improves the control of obstructive lung diseases. ${ }^{10,11}$ The effect of counseling on asthma control can be monitored by measuring lung function and with the Asthma Control Test (ACT). ${ }^{4,12,13}$ New training devices have been introduced to aid the counseling process by addressing the inspiratory flow through the pMDI, which is the most important drawback of the inhalation technique. These training devices can be considered as an add-on device to traditional pMDI verbal counseling; they provide guidance to the patient by producing an audible sound when the inspiratory flow through the pMDI is in the required range. Duration of inhalation is also important to ensure the delivery of a high portion of the emitted dose to the lungs. A newly available smartphone application could solve this by determining the duration of correct inhalation flow.

In this study, we sought to compare the effect of traditional verbal counseling on the control of asthma to the effect of advanced counseling, which included the use of a training device and a smartphone application, on the basis of spirometry and ACT scores.

\section{Methods}

A total of 371 out-patients (215 females) with asthma were recruited into the study. One hundred eightyfour subjects (102 female) were randomized to the verbal

Table 1. Steps in Correct Inhalation Technique With pMDI

Step 1. Remove the pMDI protective cap.

Step 2. Shake the pMDI before use.

Step 3. Exhale smoothly as far as comfortable.

Step 4. Put the mouthpiece of the pMDI between your teeth and cover it with lips.

Step 5. Ensure that your tongue does not block the pMDI mouthpiece.

Step 6. Press the inhaler at the start of inhalation to emit the dose.

Step 7. Maintain a slow inhalation rate until your lungs are filled.

Step 8. Remove the pMDI from your mouth and hold your breath for $5-10 \mathrm{~s}$.

Step 9. Wait for $\sim 30 \mathrm{~s}$ before taking another aerosol dose, if more than a single dose is needed.

Step 10. Rinse your mouth and brush your teeth.

Step 11. Replace the cap on the pMDI.

pMDI $=$ pressurized metered-dose inhaler

\section{QUICK LOOK}

\section{Current knowledge}

Poor lung deposition of medication from a pMDI in patients with obstructive lung disease is largely the result of incorrect inhalation technique. Verbal counseling and training in the correct inhalation technique is known to improve aerosol deposition, but most patients still do not receive an adequate dose.

\section{What this paper contributes to our knowledge}

The addition of a training device and a smartphone application to traditional verbal counseling resulted in significant improvements in lung function and asthma control compared to traditional verbal counseling alone. Greater improvements in Asthma Control Test scores were also observed in the advanced counseling group compared with the verbal counseling group.

counseling group (control group), and 187 subjects (113 female) were randomized to verbal counseling plus the use of a pMDI training device (advanced counseling group), which consisted of the Trainhaler CR plus Flo-Tone CR (Clement Clarke International, Harlow, United Kingdom) and the Trainhaler Buddy smartphone application (Clin-ecal, Manchester, United Kingdom). The study was conducted in accordance with national and institutional ethical standards for research. Ethical approval for this study was obtained (REC-H-PhBSU-18001).

Patients were excluded if they had any neurological condition that could affect their learning ability, were medically unstable, or were unable to perform the pulmonary function tests correctly after training. All subjects recruited into the study had been previously prescribed a pMDI containing short-acting bronchodilators plus inhaled corticosteroids; some subjects were receiving short-acting bronchodilators without corticosteroids, and a small proportion of subjects were receiving montelukast tablets in addition to the pMDI.

All subjects attended 3 clinic visits, with each visit 1 month apart, and each subject received verbal counseling on how to use the pMDI at each visit. Verbal counseling consisted of the 11 steps shown in Table 1. All subjects performed 3 pulmonary function test maneuvers using a spirometer (One Flow; Clement Clarke International) before starting the training session, and the highest record was taken. Subjects were then asked to show the investigator their pMDI inhalation technique using an empty inhaler. The investigator noted any errors performed by the subjects and then educated them in the correct inhalation 
technique by demonstrating all of the steps using an empty pMDI.

In addition to verbal counseling, the advanced counseling group received the training device and smartphone application. They were trained to inhale from the training device at an inspiratory flow that produced the sound of a whistle from the device, which signaled proper inspiratory flow through the pMDI ; subjects were asked to maintain the whistle sound for at least $5 \mathrm{~s}$. The smartphone application recorded the duration of correct inhalation flow according to the tone produced by the training device. Subjects continued to use the training device between visits. At the end of the training session, all subjects received 2 puffs of salbutamol (Ventolin pMDI; GlaxoSithKline, Philadelphia, Pennsylvania) at a nominal dose of $100 \mu \mathrm{g}$ salbutamol per puff. The pulmonary function test was repeated 15 min after administration of the bronchodilator. At each visit, the percent of predicted $\mathrm{FEV}_{1}$ was measured before and after receiving salbutamol, and the number of correct achievements of the pMDI technique steps was also recorded.

Subjects were told not to take medications such as theophylline, long-acting $\beta_{2}$ agonists, short-acting $\beta_{2}$ agonists, or short-acting anticholinergics before the training visit for periods of $24 \mathrm{~h}, 12 \mathrm{~h}, 6 \mathrm{~h}$, and $8 \mathrm{~h}$, respectively, to avoid interference with spirometry measurements.

At the first visit, baseline readings for spirometry and the number of errors in each step were recorded, and inspiratory flow through the pMDI was measured with an inspiratory flow meter (Clement Clarke International). These measurements were repeated at the next 2 visits. Each subject also completed the ACT at each visit, which consists of 5 questions on activity limitation, shortness of breath, waking up as a result of symptoms, need for extra bronchodilators, and self-evaluation of asthma control. Subjects rate each of these on a scale of 1 to 5 (where 1 is not controlled at all and 5 is highly controlled). The Asthma Control Score is the sum of all the scores. In this study, the Asthma Control Score was used to determine whether control had improved between visits.

\section{Statistical Analysis}

Analysis of results was performed using the Student $t$ test for between-group and within-group comparisons. A repeated measure analysis of variance test with least significant difference correction was used to compare the effect of treatment throughout the 3 visits and between groups. Chi-square test was used for analysis of the correct achievement of each training step between both groups (SPSS 23, SPSS, Chicago, Illinois).

\section{Results}

The mean \pm SD ages of subjects in the verbal counseling and advanced counseling groups were $45 \pm 9.7 \mathrm{y}$ and $49 \pm 8.4 \mathrm{y}$, respectively, and the mean \pm SD heights were $165 \pm 12.6 \mathrm{~cm}$ and $171 \pm 10.2 \mathrm{~cm}$, respectively.

The mean values for lung function, inspiratory flow, and Asthma Control Score and the mean number of correct achievements are presented in Tables 2 and 3 and the figures. Lung function results $\left(\mathrm{FEV}_{1} \%, \mathrm{FEV}_{1} / \mathrm{FVC}\right.$, and peak expiratory flow percent of predicted) were significantly $(P<.001)$ improved at the second and third clinic visits compared to the first visit for the advanced counseling group. Significant $(P<.001)$ improvements in the verbal counseling group were seen at visit 3 compared to visit 1 (Table 2 and Fig. 1), but there was no improvement at visit 2 compared to visit 1 . However, the change in $\mathrm{FEV}_{1} \%$ was significant $(P<.05)$ between visit 1 and visit 2 , but this was not significant between visit 2 and visit 3 for the verbal group (Table 2).

The number of correct achievements of inhaler technique steps was significantly $(P<.001)$ increased after each visit, but the number of subjects who achieved step 7 correctly was significantly higher $(P<.001)$ in the advanced counseling group (Table 2 and Fig. 2). ACT and inspiratory flow through the pMDI improved significantly $(P<.001)$ in both groups at visit 2 and visit 3 compared to visit 1 . ACT scores in the advanced counseling group were significantly $(P<.001)$ better than that of the verbal group at visit 2 and visit 3 , but there was no significant difference between the 2 groups at visit 1 (Table 2 and Fig. 3 ). In addition, inspiratory flow through the pMDI in the advanced counseling group improved significantly more than in the verbal counseling group at visit 2 and visit 3 , while it was significantly $(P<.001)$ worse than that in the verbal counseling group at the first visit (Table 2 and Fig. 4).

The percentage of subjects with an ACT Score that improved by 3 or more points after 1 month was higher in the advanced counseling group (52.5\%) than in the verbal counseling group $(34.8 \%)$. In the second month, this increased to $67.9 \%$ and $49.5 \%$ for the advanced counseling and verbal counseling groups, respectively (Table 2 and Fig. 5).

\section{Discussion}

Overall, the use of a pMDI training device and a smartphone application in conjunction with traditional verbal counseling reduced the frequency of inhaler technique errors. This combination significantly improved all of the studied parameters compared to traditional verbal counseling alone. These improvements resulted in a gradual improvement in pulmonary function. This is very impor- 


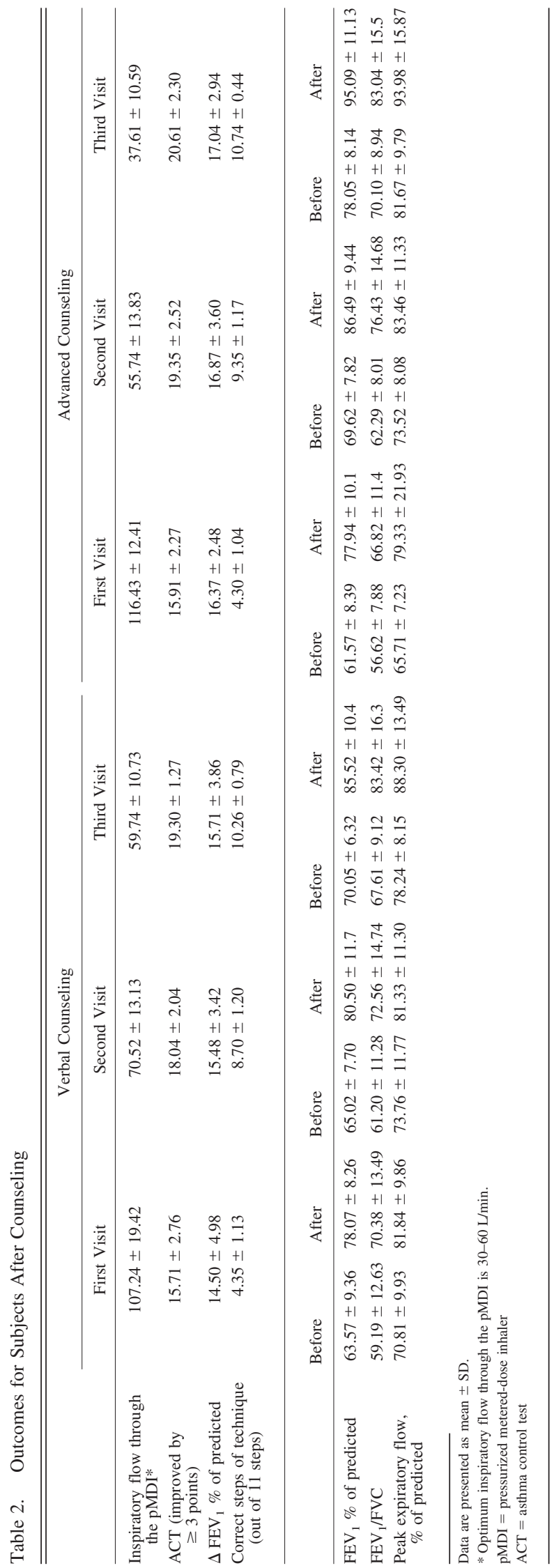

tant for obstructive lung disease patients because disease control is the main target for asthma therapy. ${ }^{14}$ The inability of patients to use their pMDI properly, as reflected by poor inhalation technique, has a great impact on disease control. ${ }^{15}$ It is estimated that up to $94 \%$ of such patients fail to use their pMDI correctly, compared to $84 \%$ of patients who fail to use dry powder inhalers correctly. ${ }^{5,16-18}$

Previous research has highlighted the need for training and education to improve aerosol therapy in patients. 3,4 Training subjects to use a pMDI correctly through verbal counseling had a significant effect on asthma control; however, a large percentage of subjects failed to maintain the correct inhalation technique and could forget their training days after counseling.4,5,19 The results of our study were consistent with these findings, as shown by the lower number of subjects with improved asthma control (expressed as the percentage of subjects with increases of $\geq 3$ ACT points ${ }^{12,13}$ ) in the verbal counseling group compared to the advanced counseling group.

Improving the ACT score is an indicator of the control of asthma as evidenced by reduced limitations in daily activity, reduced need for medication, and less frequent asthma symptoms. The significant improvement of ACT noted in the advanced counseling group compared to the verbal counseling group could be due the unlimited access to the training device and smartphone application at home. This allowed subjects to check and correct their inhalation technique whenever they wished, rather than only at counseling sessions.

Alternative standardized tools to the ACT for the assessment of asthma control (eg, the Asthma Control Questionnaire) have been released. The purpose of these tools is to measure the effect of counseling in the short term. They have different scoring systems and a different number of evaluating questions; however, the ACT has been reported to have greater power to determine levels of control of asthma compared than the Asthma Control Questionnaire. ${ }^{20}$

Differences in the percent of predicted $\mathrm{FEV}_{1}$, percent of predicted peak expiratory flow, and $\mathrm{FEV}_{1} / \mathrm{FVC}$ from visit 1 to visit 2 were significant $(P<.001)$ for the advanced counseling group but not for the verbal counseling group. This indicates that using a training device and a smartphone application in conjunction with verbal counseling can, potentially, rapidly enhance asthma control. Significant improvements $(P<.001)$ in the verbal counseling group started to appear by the third visit.

The mean number of correct achievements of inhalation technique steps increased significantly $(P<.001)$ in both groups, with overall higher percentages in the advanced counseling group. The main differences were noted in step 6 (in which the subject starts inhaling at the same time as pressing the pMDI) and in step 7 (in which the subject must inhale slowly). The advanced counseling group gained 
Table 3. Correct Performance of Inhalation Technique With pMDI

\begin{tabular}{|c|c|c|c|c|c|c|}
\hline & \multicolumn{3}{|c|}{ Verbal Counseling } & \multicolumn{3}{|c|}{ Advanced Counseling } \\
\hline & Visit 1 & Visit 2 & Visit 3 & Visit 1 & Visit 2 & Visit 3 \\
\hline Step 1. Remove the pMDI protective cap. & 100 & 100 & 100 & 100 & 100 & 100 \\
\hline Step 2. Shake the pMDI before use. & 57 & 84 & 98 & 49 & 94 & 98 \\
\hline Step 3. Exhale smoothly as far as comfortable. & 14 & 61 & 83 & 9 & 58 & 86 \\
\hline $\begin{array}{l}\text { Step } 4 \text {. Put the mouthpiece of the pMDI } \\
\text { between your teeth and cover it with } \\
\text { lips. }\end{array}$ & 23 & 84 & 100 & 25 & 92 & 100 \\
\hline $\begin{array}{l}\text { Step } 5 \text {. Ensure that your tongue does not } \\
\text { block the pMDI mouthpiece. }\end{array}$ & 41 & 89 & 100 & 35 & 91 & 100 \\
\hline $\begin{array}{l}\text { Step 6. Press the inhaler at the start of } \\
\text { inhalation to emit the dose. }\end{array}$ & 7 & 64 & 91 & 12 & 72 & 96 \\
\hline $\begin{array}{l}\text { Step 7. Maintain a slow inhalation rate until } \\
\text { your lungs are filled. }\end{array}$ & 0 & 52 & 74 & 0 & 71 & 92 \\
\hline $\begin{array}{l}\text { Step 8. Remove the pMDI from your mouth } \\
\text { and hold your breath for } 5-10 \mathrm{~s} \text {. }\end{array}$ & 37 & 92 & 100 & 29 & 96 & 100 \\
\hline $\begin{array}{l}\text { Step 9. Wait for } \sim 30 \mathrm{~s} \text { before taking another } \\
\text { aerosol dose, if more than a single } \\
\text { dose is needed. }\end{array}$ & 43 & 87 & 98 & 51 & 95 & 99 \\
\hline $\begin{array}{l}\text { Step 10. Remove your mouth and brush your } \\
\text { teeth. }\end{array}$ & 17 & 61 & 86 & 12 & 49 & 89 \\
\hline Step 11. Replace the cap on the pMDI. & 100 & 100 & 100 & 100 & 100 & 100 \\
\hline
\end{tabular}

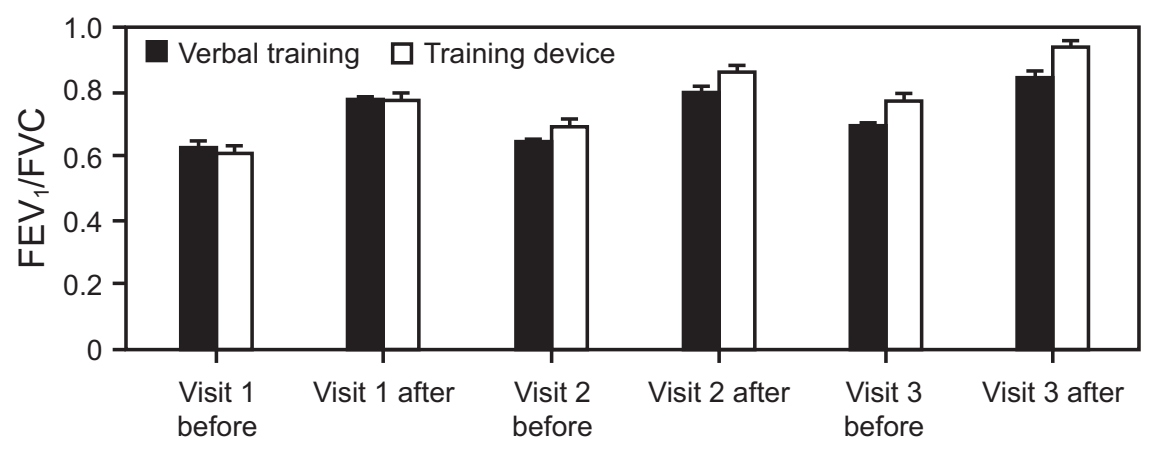

Fig. 1. Mean \pm SD FEV $1 / F V C \%$ in each group before and after each visit.

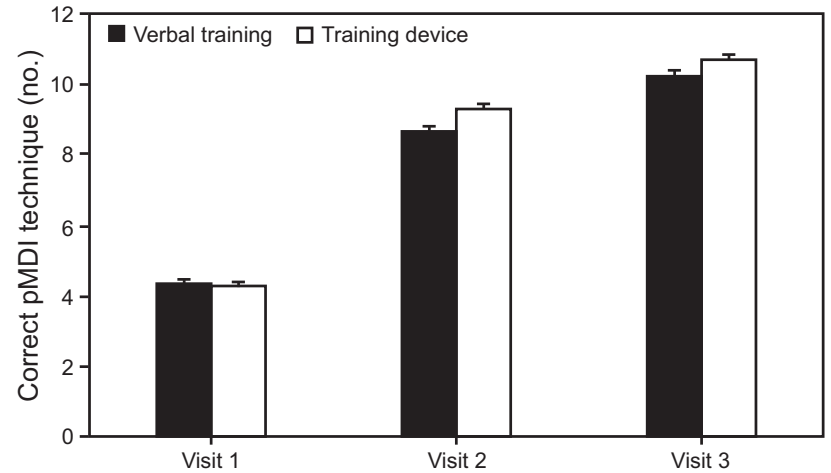

Fig. 2. Mean $\pm \mathrm{SD}$ number of correct pMDI technique achievement in each group at each visit. pMDI = pressurized metereddose inhaler.

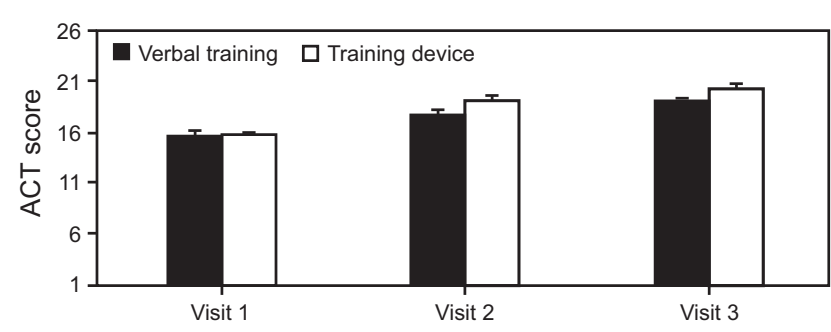

Fig. 3. Mean $\pm S D$ results of the Asthma Control Test (ACT) in each group at each visit.

a significantly better $(P<.001)$ number of correct achievements compared with the verbal counseling group. ${ }^{4}$ Some steps were completely correct from the first visit because 


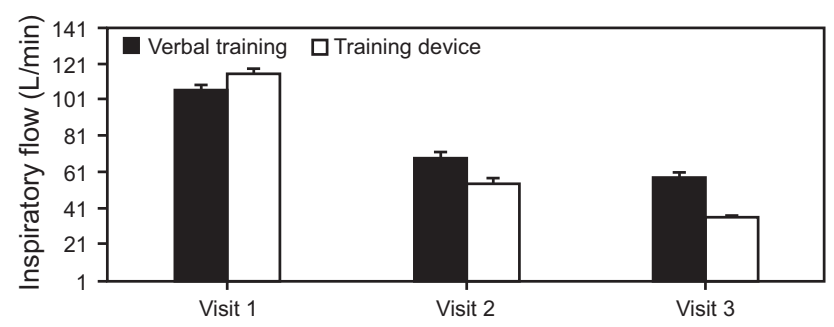

Fig. 4. Mean $\pm S D$ inspiratory flow in each group at each visit.

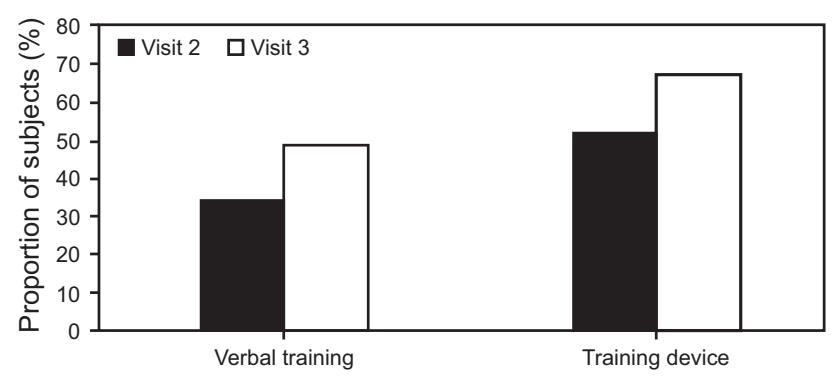

Fig. 5. Percentage of subjects who increased their Asthma Control Test score by $\geq 3$ points.

they were easy and logical to perform (eg, step 1 is to remove the pMDI protective cap, and step 11 is to replace the cap). ${ }^{5,8,17,18}$

Errors in technique that patients exhibited have been investigated extensively and support the role of verbal training in improving overall technique, especially if the counseling is performed frequently. ${ }^{10,21,22}$ However, the effect of using the training device and smartphone application in conjunction with verbal counseling, as in our study, on reducing the number of errors committed by the subjects reflect their importance for improving inhalation technique.

Patient inhalation flow is the cornerstone of patient training and the focus of many training devices. For this reason, we recorded inspiratory flow through the pMDI in both groups at each visit. A significant $(P<.001)$ change in inspiratory flow through the pMDI was detected for both groups; however, at the second and third visits, the inspiratory flow through the pMDI was significantly $(P<.001)$ lower (better) and more often within the target range for the advanced counseling group than for the verbal counseling group. This difference could explain the significant overall improvement in the advanced counseling group, especially because the slow flow was maintained for at least $5 \mathrm{~s}$ as monitored by the smartphone application linked to the training device. The training device and the smartphone application added a sense of continuity to the counseling and were particularly useful in helping subjects maintain the correct inhalation technique in step 7 of the inhalation technique (ie, maintain a slow inhalation flow while completely filling the lungs).
In this study, the combination of acoustic feedback (ie, the whistle from the training device) and visual feedback (ie, looking at the smartphone application) helped subjects in the advanced counseling group improve their inhalation technique. This strongly suggests that redesigning the pMDI (or retrofitting a whistle to existing pMDIs to provide acoustic feedback) and linking the device to a smartphone application might help patients constantly check their technique.

\section{Limitations of the Study}

The inclusion of only asthmatic subjects could be considered a limitation of this study. This was done to reduce the anticipated degree of between-subject variation with the inclusion of subjects with other obstructive pulmonary diseases. In addition, even though the Asthma Control Questionnaire has been demonstrated to be less effective than the ACT, ${ }^{20}$ it may provide a better reflection of the effect of counseling in the short term because it is completed within 1 week compared to within 1 month for the ACT.

\section{Conclusions}

The use of a training device and smartphone application in conjunction with verbal counseling had a number of advantages over traditional verbal counseling alone. Subjects in the advanced counseling group were quicker to make improvements in the more difficult actuation-inhalation and slow, deep inhalation steps, and overall they made fewer errors in the inhalation technique. Furthermore, these subjects benefited from a gradual improvement in pulmonary function and improved asthma control compared to the group that had verbal counseling alone. We recommend adding a training device and smartphone application to continuous verbal counseling to help patients deliver their inhaled dose properly.

\section{REFERENCES}

1. Newman SP. Principles of metered-dose inhaler design. Resp Care 2005;50(9):1177-1190.

2. Tena AF, Clarà PC. Deposition of inhaled particles in the lungs. Archivos de Bronconeumología 2012;48(7):240-246.

3. Al-Showair RAM, Pearson SB, Chrystyn H. The potential of a 2Tone Trainer to help patients use their metered dose inhalers. Chest 2007; 131(6):1776-1782.

4. Nicola M, Elberry A, Sayed O, Hussein R, Saeed H, Abdelrahim M. The impact of adding a training device to familiar counselling on inhalation technique and pulmonary function of asthmatics. Adv Ther 2018;35(7):1049-1058.

5. Elgendy MO, Abdelrahim ME, Eldin RS. Potential benefit of repeated MDI inhalation technique counselling for patients with asthma. Eur J Hosp Pharm 2015;22(6):318-322.

6. van Beerendonk I, Mesters I, Mudde AN, Tan T. Assessment of the inhalation technique in outpatients with asthma or chronic obstruc- 


\section{Smartphone ApP for pMDI Inhalation Technique}

tive pulmonary disease using a metered-dose inhaler or dry powder device. J Asthma 1998;35(3):273-279.

7. Bosnic-Anticevich SZ. Inhaler device handling: have we really started to address the problem? Eur Resp J 2017;49:1700120.

8. Melani AS, Bonavia M, Cilenti V, Cinti C, Lodi M, Martucci P, et al. Inhaler mishandling remains common in real life and is associated with reduced disease control. Resp Med 2011;105(6):930-938.

9. Lavorini F, Magnan A, Dubus JC, Voshaar T, Corbetta L, Broeders $\mathrm{M}$, et al. Effect of incorrect use of dry powder inhalers on management of patients with asthma and COPD. Resp Med 2008;102(4): 593-604.

10. Saji M, Alhas J, Siraj S. Study on the impact of patient counseling on the quality of life and pulmonary function of asthmatic patients. Int J Pharm Pharm Sci 4(Suppl 5):300-304, 2012.

11. Shareef J, Sajitha M, Shastry C. Impact of pharmacist provided patient counseling on quality of life inpatients with asthma in a tertiary care teaching hospital. Int J Pharma Res Rev 2014;3(2):1-10.

12. Schatz M, Sorkness CA, Li JT, Marcus P, Murray JJ, Nathan RA, et al. Asthma Control Test: reliability, validity, and responsiveness in patients not previously followed by asthma specialists. J Allergy Clin Immun 2006;117(3):549-556.

13. Schatz M, Kosinski M, Yarlas AS, Hanlon J, Watson ME, Jhingran P. The minimally important difference of the Asthma Control Test. J Allergy Clin Immun 2009;124(4):719-723.

14. Reddel HK, Taylor DR, Bateman ED, Boulet L-P, Boushey HA, Busse WW, et al. An official American Thoracic Society/European Respiratory Society statement: asthma control and exacerbations: standardizing endpoints for clinical asthma trials and clinical practice. Am J Respir Crit Care Med 2009;180(1):59-99.
15. Alvim CG, Picinin IM, Camargos PM, Colosimo E, Lasmar LB, Ibiapina CC, et al. Quality of life in asthmatic adolescents: an overall evaluation of disease control. J Asthma 2009;46(2):186-190.

16. Ganguly A, Das AK, Roy A, Adhikari A, Banerjee J, Sen S. Study of proper use of inhalational devices by bronchial asthma or COPD patients attending a tertiary care hospital. J Clin Diagn Res: JCDR 2014;8(10):HC04.

17. Nicola M, Elberry AA, Sayed OM, Hussein RR, Abdelrahim ME. Effect of DPI's training-device on inhalation technique and clinical efficacy in asthmatics. Beni-Suef Univ J Basic Appl Sci 2018;7(2): 178-183.

18. Saeed H, Salem HF, Rabea H, Abdelrahim ME. Effect of human error, inhalation flow, and inhalation volume on dose delivery from Ellipta dry-powder inhaler. J Pharm Innov 2018;1-6.

19. Ammari WG, Chrystyn H. Optimizing the inhalation flow and technique through metered dose inhalers of asthmatic adults and children attending a community pharmacy. J Asthma 2013;50(5): 505-513.

20. Jia CE, Zhang HP, Lv Y, Liang R, Jiang YQ, Powell H, et al. The Asthma Control Test and Asthma Control Questionnaire for assessing asthma control: systematic review and meta-analysis. J Allergy Clin Immun 2013;131(3):695-703.

21. Price D, Bosnic-Anticevich S, Briggs A, Chrystyn H, Rand C, Scheuch $\mathrm{G}$, et al. Inhaler competence in asthma: common errors, barriers to use and recommended solutions. Resp Med 2013;107(1):37-46.

22. Sanchis J, Gich I, Pedersen S, Team ADMI. Systematic review of errors in inhaler use: has patient technique improved over time? Chest 2016;150(2):394-406. 